\title{
Role of tyrosine phosphatase in the modulation of pulmonary vascular tone
}

\author{
X.L. Huang*, D. El Kebir*, A.S. De Buys Roessingh*, J.C. Schneider*, L. Jacob\#, J.C. Mercier", \\ J. Dall'Ava-Santucci*, A.T. Dinh-Xuan*
}

Role of tyrosine phosphatase in the modulation of pulmonary vascular tone. X.L. Huang, D. El Kebir, A.S. De Buys Roessingh, J.C. Schneider, L. Jacob, J.C. Mercier, J. Dall'Ava-Santucci, A.T. Dinh-Xuan. C)ERS Journals Ltd 2002.

ABSTRACT: In the vascular system, synthesis of the potent vasodilator nitric oxide (NO) is tightly regulated by the constitutively expressed endothelial NO synthase (eNOS). Activity of eNOS is controlled by $\mathrm{Ca}^{2+} /$ calmodulin and various seryl/threonyl protein kinases. Less is known about the importance of phosphorylation and dephosphorylation of tyrosyl residues. Therefore the role of tyrosine phosphatase on the modulation of isolated rat pulmonary artery tone has been assessed. Inhibition of tyrosine phosphatase by sodium orthovanadate $\left(\mathrm{SOV}, 1 \times 10^{-6} \mathrm{M}\right)$ significantly: 1) increased phenylephrine-induced vasoconstriction and 2) decreased endotheliumdependent relaxation to acetylcholine, but had no effect on endothelium-independent relaxation to the NO donor, sodium nitroprusside. In phenylephrine-precontracted pulmonary arterial rings, SOV $\left(1 \times 10^{-7}-1 \times 10^{-5} \mathrm{M}\right)$ had no effect on vascular tone but significantly relaxed rings which were pretreated with the NO-synthase inhibitor, $N^{\omega}$-nitro-L-arginine-methyl ester (L-NAME). SOV-induced relaxation in the presence of L-NAME was, however, abolished by glibenclamide.

In conclusion, inhibition of tyrosine phosphatase altered pulmonary vascular tone by increasing vasoconstrictor response to phenylephrine and decreasing endotheliumdependent relaxation to acetylcholine. Furthermore, the tyrosine phosphatase inhibitor, sodium orthovanadate, exhibited original vasodilator properties which were only observed when nitric oxide synthesis was inhibited. Thus a new pathway involving the inhibitory effect of nitric oxide on a glibenclamide-sensitive diffusible relaxing factor, that might play an important role in the control of pulmonary vascular tone is described.

Eur Respir J 2002; 19: 525-529.
*Service de Physiologie-Explorations Fonctionnelles and ${ }^{\#}$ Laboratoire de Biologie Cellulaire, Centre Hospitalier Universitaire, Cochin Assistance Publique-Hôpitaux de Paris, Université Paris V, 75679 Paris cedex 14. "Service de Réanimation Pédiatrique Hôpital Robert Debré, Assistance PubliqueHôpitaux de Paris, Université Paris VII, France.

Correspondence: A.T. Dinh-Xuan, Service de Physiologie-Explorations Fonctionnelles, Centre Hospitalier Universitaire Cochin, Assistance PubliqueHôpitaux de Paris, Université Paris V, 27 rue du faubourg Saint-Jacques, 75679 Paris cedex 14, France.

Fax: 33158412345

E-mail: anh-tuan.dinh-xuan@cch.aphop-paris.fr

Keywords: Endothelium-derived hyperpolarizing factor, endothelial nitric oxide synthase, $N^{\omega}$-nitro-Larginine-methyl ester, sodium orthovanadate, tyrosine kinase, tyrosine phosphatase.

Received: September 122001 Accepted after revision November 22 2001
Pulmonary vascular tone is modulated by a variety of endothelium-derived relaxing factors including prostacyclin, nitric oxide (NO) [1, 2], and the endothelium-derived hyperpolarizing factors (EDHF) [2, 3]. NO is one of the most potent vasodilators known to date. Its synthesis is tightly regulated by intracellular free $\mathrm{Ca}^{2+}$ and the $\mathrm{Ca}^{2+}$ / calmodulin complex that, in turn, stimulate the constitutive isoform of endothelial NO synthase (eNOS). Alternatively, phosphorylation on seryl and threonyl residues by various seryl/threonyl kinases is also thought to modulate eNOS activity $[4,5]$.

Shear stress is the major physiological factor modulating pulmonary vascular tone in health and disease. The underlying mechanism most likely involves synthesis and release of NO from pulmonary endothelial cells. Recent evidence suggests that endothelial production of NO is increased in response to shear stress through tyrosine phosphorylation via a calcium-independent pathway in the systemic circulation $[4,6]$. Contradictory studies alternatively suggest that tyrosine phosphorylation of eNOS might also reduce its activity [7]. Whether or not alteration of phosphorylation and/or dephosphorylation of tyrosyl residues of eNOS affects its activity in the pulmonary artery has yet to be investigated.

In various vascular beds, EDHF causes relaxation through vascular smooth muscle hyperpolarization [3]. The identity of EDHF is still under debate. Early evidence has suggested that adenosine triphosphate (ATP)-dependent potassium $\left(\mathrm{K}_{\mathrm{ATP}}\right)$ channels are activated by EDHF [8-10], whereas recent evidence further suggests that EDHF is a product of cytochrome P-450 enzymes [11, 12] which cause relaxation by activating large conductance calcium-activated potassium $\left(\mathrm{K}_{\mathrm{Ca}}\right)$ channels [11-13]. The physiological role of EDHF in pulmonary vessels is still uncertain, although there is circumstantial evidence to suggest that EDHF might play an important role in transitional pulmonary circulation [14].

The aim of this study was to further elucidate the role of tyrosine phosphorylation in NO and EDHF 
signalling pathways in the pulmonary circulation. The authors have more specifically studied the effect of sodium orthovanadate (SOV), a tyrosine phosphatase inhibitor, which has been demonstrated to activate NOS through tyrosine phosphorylation-dependent mechanisms in the systemic circulation [4, 15]. It was found that SOV significantly altered pulmonary vascular tone by reducing NO-mediated pulmonary vasodilatation and increasing the vasodilator effects of EDHF.

\section{Materials and methods}

Male Sprague-Dawley rats (250-275 g) were anaesthetized intraperitoneally with thiopental sodium $\left(80 \mathrm{mg} \cdot \mathrm{kg}^{-1}\right)$. The pulmonary arteries (PA) were immediately dissected and placed in cold Krebs solution: $\mathrm{NaCl} 118, \mathrm{KCl} 5.9, \mathrm{MgSO}_{4} 1.2, \mathrm{CaCl}_{2} 2.5$, $\mathrm{NaH}_{2} \mathrm{PCO}_{4} 1.2$, glucose 5.6, $\mathrm{NaHCO}_{3} 25.5(\mathrm{nM})$. The arteries were cleaned of perivascular tissue and cut into rings $2.5 \mathrm{~mm}$ in length. The rings were suspended between two wire hooks. One of the hooks was fixed to a support in an isolated organ bath containing $20 \mathrm{~mL}$ of Krebs solution maintained at $37^{\circ} \mathrm{C}$ and gassed with a mixture of $95 \%$ oxygen $\left(\mathrm{O}_{2}\right)$ and $5 \%$ carbon dioxide $\left(\mathrm{CO}_{2}\right)$. Each vascular segment was set at a resting tension for optimal length development ranging from $0.7-1.0 \mathrm{~g}$. The rings were then allowed to equilibrate for $60 \mathrm{~min}$. After equilibration, three studies were performed.

\section{Experimental studies}

After contraction with phenylephrine $\left(1 \times 10^{-7}\right.$ $\left.1 \times 10^{-6} \mathrm{M}\right)$ to obtain a stable plateau of tension, the rings were challenged with increasing concentrations of acetylcholine $\left(1 \times 10^{-7}-1 \times 10^{-5} \mathrm{M}\right)$. Sodium nitroprusside, a NO donor $\left(1 \times 10^{-4} \mathrm{M}\right)$, was added at the end of the experiments to maximally relax pulmonary vascular smooth muscle. PA rings were divided into two groups, one group were treated with SOV $\left(1 \times 10^{-6} \mathrm{M}\right)$ for $15 \mathrm{~min}$, whereas the other group were treated with the solvent (distilled water) and served as controls. SOV was first added $15 \mathrm{~min}$ before contraction to phenylephrine to study the effects of SOV on phenylephrine-induced contraction.

In a separate set of experiments, SOV was added after the plateau of contraction to phenylephrine was reached, incubation with SOV then lasted for $15 \mathrm{~min}$ before endothelium-dependent relaxation to acetylcholine $\left(1 \times 10^{-7}-1 \times 10^{-5} \mathrm{M}\right)$ and endotheliumindependent relaxation to the NO donor, sodium nitroprusside $\left(1 \times 10^{-4} \mathrm{M}\right)$, were assessed.

In a third set of experiments, the effects of increasing concentrations of SOV $\left(1 \times 10^{-7}-1 \times 10^{-5} \mathrm{M}\right)$ on phenylephrine-precontracted pulmonary vascular rings was assessed. The rings were divided into three groups: 1) untreated; 2) treated with $N^{\omega}$-nitroL-arginine methyl ester (L-NAME) $\left(1 \times 10^{-3} \mathrm{M}\right)$; and 3$)$ treated with L-NAME $\left(1 \times 10^{-3} \mathrm{M}\right)$ and glibenclamide $\left(1 \times 10^{-5} \mathrm{M}\right)$.

\section{Drugs}

All drugs were purchased from Sigma (Saint Quentin-Fallavier, France). SOV, phenylephrine, acetylcholine, sodium nitroprusside and L-NAME, were dissolved in distilled water, whereas glibenclamide was dissolved in dimethyl sulphoxide which, by itself had no effect on tone of isolated pulmonary vessels.

\section{Data analysis}

The magnitude of contraction by phenylephrine was expressed in $\mathrm{mg}$ (mean \pm SEM), $\mathrm{n}$ is the number of pulmonary vascular rings. Relaxation and contraction were expressed as the percentage decrease or increase in tone from the plateau of precontraction obtained with phenylephrine $\left(1 \times 10^{-6} \mathrm{M}\right)$. The mean \pm SEM of each set of experimental data were used to construct the concentration-response curves to various pharmacological substances. Statistical analysis was performed using the nonparametric Wilcoxon signed-rank test to compare results obtained on rings with and without endothelium that were challenged with various inhibitors or agonists and their controls. Values were considered statistically significant when $\mathrm{p}<0.05$.

\section{Results}

Sodium orthovanadate increased phenylephrineinduced contraction

SOV $\left(1 \times 10^{-6} \mathrm{M}\right)$, by itself, had no contractile effect on basal tone but significantly increased the magnitude of contraction in all $\mathrm{PA}$ rings $(\mathrm{n}=10)$ in response to phenylephrine $\left(1 \times 10^{-7} \mathrm{M}\right)(614 \pm 78 \mathrm{mg}$ versus $745 \pm 90 \mathrm{mg} ; \mathrm{p}<0.001)$ and $1 \times 10^{-6} \mathrm{M} \quad(767 \pm 102 \mathrm{mg}$ versus $960 \pm 123 \mathrm{mg} ; \mathrm{p}<0.0001)$.

In PA rings without endothelium, SOV $\left(1 \times 10^{-6} \mathrm{M}\right)$, also significantly affected the contractile responses to phenylephrine, increasing maximal tension from $851 \pm 168 \mathrm{mg}$ to $1010 \pm 193 \mathrm{mg}$ (in control and treated rings, respectively; $\mathrm{p}<0.01)$.

\section{Sodium orthovanadate reduced endothelium-dependent} relaxation to acetylcholine

In PA rings precontracted with phenylephrine $\left(1 \times 10^{-6} \mathrm{M}\right)$ pretreatment with $\mathrm{SOV}\left(1 \times 10^{-6} \mathrm{M}\right)$ significantly decreased endothelium-dependent relaxation to acetylcholine (maximal relaxation $48 \pm 9 \%$ in treated $\mathrm{PA}$ rings versus $75 \pm 8 \%$ in controls, $\mathrm{p}<0.05)$ (fig. 1).

Endothelium-dependent relaxation in response to sodium orthovanadate

Increasing concentrations of SOV $\left(1 \times 10^{-7}-\right.$ $\left.1 \times 10^{-5} \mathrm{M}\right)$ had no significant relaxing effect on PA 


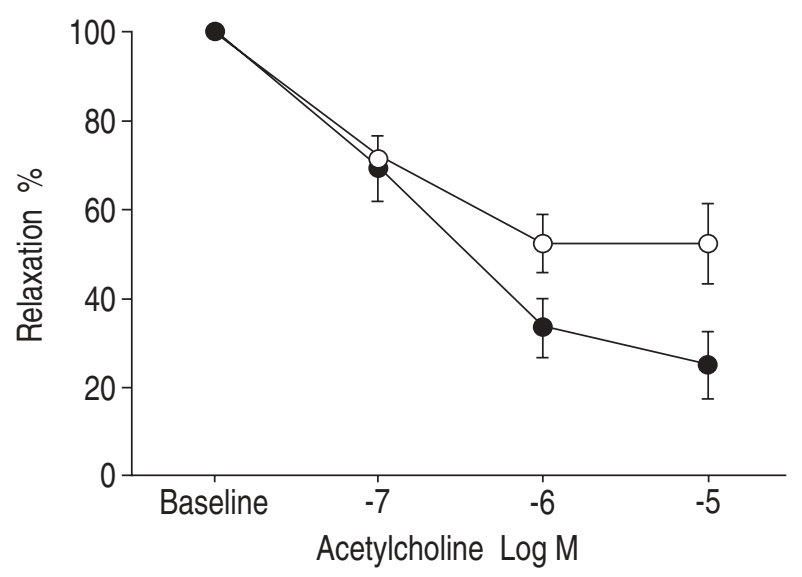

Fig. 1.-Effect of sodium orthovanadate (SOV) on acetylcholineinduced relaxation. Cumulative concentration-response curves for acetylcholine were made in the rings pretreated with SOV and in control rings. Relaxation was presented as percentage of precontraction with phenylephrine $\left(1 \times 10^{-6} \mathrm{M}\right)$. Data was expressed as mean \pm SEM. $n=8$ each. 0 : control; $\bigcirc$ : with $\mathrm{SOV}$ $\left(1 \times 10^{-6} \mathrm{M}\right)$.

rings precontracted with phenylephrine $\left(1 \times 10^{-6} \mathrm{M}\right)$ (fig. 2). However, pretreatment with L-NAME $\left(1 \times 10^{-3} \mathrm{M}\right)$ caused relaxation of PA rings challenged with increasing concentrations of SOV $(21 \pm 5 \%$ versus $3 \pm 2 \%$ for $1 \times 10^{-7} \mathrm{M}, 28 \pm 7 \%$ versus $5 \pm 3 \%$ for $1 \times 10^{-6} \mathrm{M}$ and $30 \pm 8 \%$ versus $6 \pm 4 \%$ for $1 \times 10^{-5} \mathrm{M}$, $\mathrm{p}<0.05$ respectively). L-NAME-induced endotheliumdependent relaxation to SOV was completely abolished by glibenclamide $\left(1 \times 10^{-5} \mathrm{M}\right)$ (fig. 2).

In PA rings without endothelium, SOV $\left(1 \times 10^{-7}\right.$ $1 \times 10^{-5} \mathrm{M}$ ) similarly failed to induce any relaxing effect on PA rings precontracted with phenylephrine $\left(1 \times 10^{-6} \mathrm{M}\right)$. However, unlike PA rings with endothelium, neither L-NAME nor glibenclamide significantly

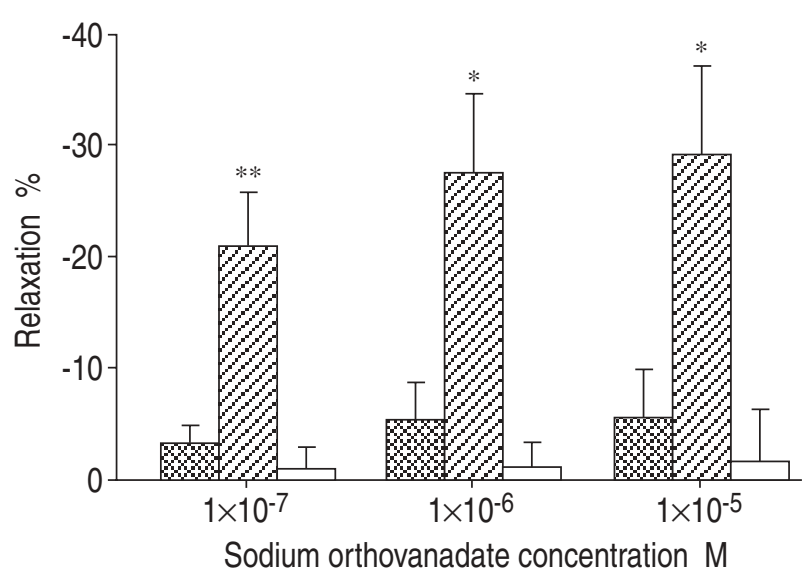

Fig. 2.-Effect of sodium orthovanadate (SOV) on pulmonary arterial rings with endothelium in the presence of: $\mathbb{Z}: N^{\omega}$-nitro-Larginine-methyl ester (L-NAME) $\left(1 \times 10^{-3} \mathrm{M}, \mathrm{n}=8\right)$; and $\square$ : a combination of L-NAME $\left(1 \times 10^{-3} \mathrm{M}\right)$ and glibenclamide $\left(1 \times 10^{-5} \mathrm{M}, \mathrm{n}=7\right)$; $\mathbf{0}$ : control, $\mathrm{n}=8$. Relaxation in response to $\mathrm{SOV}$ $\left(1 \times 10^{-7}, 1 \times 10^{-6}\right.$ and $\left.1 \times 10^{-5} \mathrm{M}\right)$ was expressed as percentage from precontraction to phenylephrine $\left(1 \times 10^{-6} \mathrm{M}\right)$. Data was expressed as mean \pm SEM of $\mathrm{n}$ experiments. ${ }^{*}: \mathrm{p}<0.05 ; * * \mathrm{p}<0.01$.

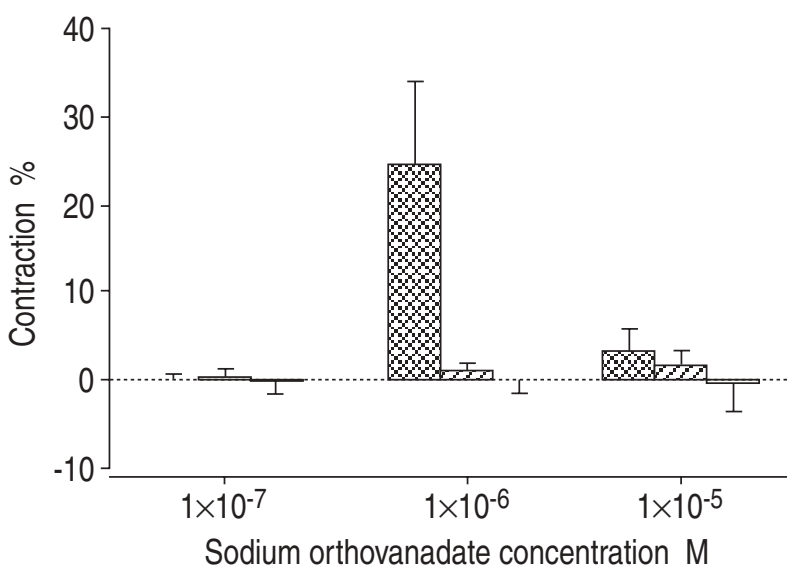

Fig. 3.-Effect of sodium orthovanadate (SOV) on pulmonary arterial rings without endothelium in the presence of: $\mathbb{Z}: N^{\omega}$-nitroL-arginine-methyl ester (L-NAME) $\left(1 \times 10^{-3} \mathrm{M}\right)$; and $\square$ : a combination of L-NAME $\left(1 \times 10^{-3} \mathrm{M}\right)$ and glibenclamide $\left(1 \times 10^{-5} \mathrm{M}\right)$; control. Response to SOV $\left(1 \times 10^{-7}, 1 \times 10^{-6}\right.$ and $\left.1 \times 10^{-5} \mathrm{M}\right)$ was expressed as percentage from precontraction to phenylephrine $\left(1 \times 10^{-6} \mathrm{M}\right)$. Vasoconstriction was represented by positive values whereas vasorelaxation was represented by negative values. $n=4$. Data was expressed as mean \pm SEM of $n$ experiments.

altered the lack of vasorelaxant effects of SOV in PA rings without endothelium (fig. 3).

Effect of sodium orthovanadate on endotheliumindependent relaxation to sodium nitroprusside

In PA rings precontracted with phenylephrine $\left(1 \times 10^{-6} \mathrm{M}\right)$, SOV $\left(1 \times 10^{-6} \mathrm{M}\right)$ had no effect on endothelium-independent relaxation to the $\mathrm{NO}$ donor sodium nitroprusside.

\section{Discussion}

It has been demonstrated that inhibition of tyrosine phosphatase by SOV significantly altered pulmonary vascular tone by increasing vasoconstrictor response to phenylephrine and decreasing the endotheliumdependent vasodilator response to acetylcholine. As the increase in vasoconstrictor response to phenylephrine was also present in PA rings without endothelium, the procontractile effect of SOV would be best explained by a direct action on pulmonary vascular smooth muscle rather than putative release of endothelial-derived vasoconstrictors.

As reported previously in systemic circulation, inhibition of tyrosine phosphatase by SOV markedly increased vasoconstrictor responses to phenylephrine $[16,17]$. This observation is consistent with the fact that phosphorylation of tyrosyl residues by tyrosine kinase is implicated in the mechanisms leading to constriction of vascular smooth muscle [18-22]. Vasoconstriction occurs as a result of activation of myosin light chain kinase (MLCK) that, in turn, phosphorylates myosin light chain, thereby enabling formation of actin-myosin cross bridges resulting in vascular smooth muscle contraction [23]. The potent tyrosine kinase inhibitor, genistein [24] significantly 
inhibited contractile response to sodium fluoride, a direct G-protein activator, in rat aorta [16]. SOV, a selective inhibitor of tyrosine phosphatase, by maintaining phosphorylation of tyrosine residues [25-30], may increase the activity of G-proteins thereby favouring vasoconstriction. By contrast, genistein and SOV had no significant effect on MLCK [17], protein kinase-C [16, 24] and protein kinase-A [24] activities. The inhibitory effect of genistein on agonist-induced contraction is still present in calcium-free medium [16]. Furthermore, the calcium channel blocker verapamil has no effect on the potentiation of agonist-induced contraction by phenylarsine oxide, an inhibitor of tyrosine phosphatase [31]. This suggests that calcium released from intracellular stores rather then calcium influx might, at least in part, mediate the vasoconstrictor effect of tyrosine kinase.

Acetylcholine causes vasodilatation through activation of eNOS and NO release. The present study provides circumstantial evidence suggesting that inhibition of eNOS through tyrosine phosphorylation may account for the inhibitory effect of SOV on acetylcholine-induced relaxation.

Previous reports have shown that both tyrosinephosphatase inhibitors, SOV and phenylarsine oxide, caused endothelium-dependent vasodilatation in pig coronary and in rabbit carotid arteries respectively $[4,15]$. In this study, only a moderate endotheliumdependent vasodilatation of rat pulmonary arteries in response to increasing concentrations of SOV was found. Pretreatment with L-NAME, however, greatly increased the vasodilator response to SOV, that was fully attenuated by glibenclamide. This suggests that NO exerts an inhibitory effect on a glibenclamidesensitive vasodilator that can be activated by SOV. This vasorelaxing factor most likely derives from the endothelium, as PA rings, without endothelium failed to relax in response to $\mathrm{SOV}$ after inhibition of $\mathrm{NO}$ synthesis by L-NAME. As glibenclamide only inhibited the L-NAME-induced vasorelaxing response to SOV in PA rings with endothelium, the authors suggest that the putative endothelial-derived relaxing factor implicated in this study is one of the $\operatorname{EDHF}(\mathrm{s})$. To date the release of EDHF, induced by acetylcholine, has been seen only after inhibition of eNOS and cyclooxygenase [3, 11]. In coronary arteries, EDHF is likely to act through the opening of $\mathrm{K}_{\mathrm{Ca}}$ channels rather then $\mathrm{K}_{\mathrm{ATP}}$ channels $[11,12]$. In the present study, the vasodilator effect of SOV, which is seen only in the presence of L-NAME, suggests that inhibition of NO synthesis favours the release of a vasodilator substance sensitive to glibenclamide. This compensatory mechanism may play an important role in vascular disorders characterized by impairment of NO synthesis and/or release.

In conclusion, it has been demonstrated that inhibition of tyrosine phosphatase increases the vasocontractile response to phenylephrine and reduces endothelium-dependent relaxation to acetylcholine. Surprisingly, sodium orthovanadate also causes vasodilatation, which is probably due to the release of endothelium-derived hyperpolarizing factor, an effect which can only be observed during inhibition of nitric oxide synthesis.

\section{References}

1. Dinh-Xuan AT. Endothelial modulation of pulmonary vascular tone. Eur Respir J 1992; 5: 757-762.

2. Lévy M, Sabry S, Mercier JC, Dinh-Xuan AT. Rôles des facteurs vasoactifs synthétisés par l'endothélium dans 1'hypertension artérielle pulmonaire. Arch Pédiatr 1997; 4: 271-277.

3. Galand CJ, Plane F, Kemp BK, Cocks TM. Endothelium-dependent hyperpolarization: a role in the control of vascular tone. Trends Pharmacol Sci 1995; 16: 23-30.

4. Fleming I, Bauersachs J, Fisslthaler B, Busse R $\mathrm{Ca}^{2+}$-independent activation of the endothelial nitric oxide synthase in response to tyrosine phosphatase inhibitors and fluid shear stress. Circ Res 1998; 82: 686-695.

5. Corson MA, James NL, Latta SE, Nerem RM, Berk $\mathrm{BC}$, Harison DG. Phosphorylation of endothelial nitric oxide synthase in response to fluid shear stress. Circ Res 1996; 79: 984-991.

6. Ayajiki K, Kindermenn M, Hecker M, Fleming I, Busse R. Intracellular $\mathrm{pH}$ and tyrosine phosphorylation but not calcium determines shear stress-induced nitric oxide production in native endothelial cells. Circ Res 1996; 78: 750-758.

7. García-Cardena G, Fan G, Stern DF, Lin J, Sessa WC. Endothelial nitric oxide synthase is regulated by tyrosine phosphorylation and interacts with caveolin1. J Biol Chem 1996; 271: 27237-27240.

8. Standen NB, Quayle JM, Davies NW, Brayden JE, Huang Y, Nelson MT. Hyperpolarizing vasodilators activate ATP-sensitive $\mathrm{K}^{+}$channels in arterial smooth muscle. Science 1989; 245: 177-180.

9. Brayden JE. Membrane hyperpolarization is a mechanism of endothelium-dependent cerebral vasodilation. Am J Physiol 1990; 259: H668-H673.

10. Brayden JE. Hyperpolarization and relaxation of resistance arteries in response to adenosine diphosphate. Distribution and mechanism of action. Circ Res 1991; 69: 1415-1420.

11. Nishikawa IY, Step DW, Chilian WM. In vivo location and mechanism of EDHF-mediated vasodilatation in canine coronary microcirculation. $\mathrm{Am}$ J Physiol Heart Circ Physiol 1999; 277: H1252-H1259.

12. Widmann MD, Weintraub NL, Fudge JL, Brooks LA, Dellsperger KC. Cytochrome P-450 pathway in acetylcholine-induced canine coronary microvascular vasodilation in vivo. Am J Physiol Heart Circ Physiol 1998; 274: H283-H289.

13. Li PL, Zou AP, Campbell WB. Regulation of potassium channels in coronary arterial smooth muscle by endothelium-derived vasodilators. Hypertension 1997; 29: 262-267.

14. Lévy M, Souil E, Sabry S, et al. Maturational changes of endothelial vasoactive factors and pulmonary vascular tone at birth. Eur Respir J 2000; 15: 158-165.

15. Nakaike $\mathrm{R}$, Shimokawa $\mathrm{H}$, Owada MK, et al. Vanadate causes synthesis of endothelium-derived NO via pertussis toxin-sensitive $\mathrm{G}$ protein in pigs. Am J Physiol Heart Circ Physiol 1996; 271: H296H320.

16. Abebe W, Agrawal DK. Role of tyrosine kinase in 
norepinephrine-induced contraction of vascular smooth muscle. J Cardiovasc Pharmacol 1995; 26: $153-159$

17. Jin NJ, Siddiqui RA, English D, Rhoades RA. Communication between tyrosine kinase pathway and myosin light chain kinase pathway in smooth muscle. Am J Physiol Heart Circ Physiol 1996; 271 : H1348-H1355.

18. Di Salvo J, Steusloff A, Semenchuck L, Satoh S, Kolquist K, Pfitzer G. Tyrosine kinase inhibitors suppress agonist-induced contraction in smooth muscle. Biochem Biophys Res Commun 1993; 190: 968-974.

19. Tsuda T, Kawahara Y, Shii K, Koide M, Ishida Y, Yokoyama M. Vasoconstrictor-induced proteintyrosine phosphorylation in cultured vascular smooth muscle cells. FEBS Lett 1991; 285: $44-48$.

20. Koide M, Kawahara Y, Tsuda T, Ishida Y, Shii K, Yokoyama M. Endothelin-1 stimulates tyrosine phosphorylation and the activities of two mitogenactivated protein kinases in cultured vascular smooth muscle cells. J Hypertens 1992; 10: 1173-1182.

21. Molloy CJ, Taylor DS, Weber H. Angiotensin-II stimulation of rapid protein tyrosine phosphorylation and protein kinase activation in rat aortic smooth muscle cells. J Biol Chem 1993; 268: 7338-7345.

22. Hollenberg MD. Tyrosine kinase pathways and the regulation of smooth muscle contractility. Trends Pharmacol Sci 1994; 15: 108-114.

23. Kamm KE, Stull JT. The function of myosin and myosin light chain kinase phosphorylation in smooth muscle. Annu Rev Pharmacol Toxicol 1985; 25: 593620.
24. Akiyama T, Ishida J, Nakgawa S, et al. Genistein, a specific inhibitor of tyrosine-specific protein kinases. J Biol Chem 1987; 262: 5592-5595.

25. Laniyonu A, Saiffeddine M, Ahmad S, Hollenberg MD. Regulation of vascular and gastric smooth muscle contractility by pervanadate. Br J Pharmacol 1994; 113: 403-410.

26. Heffetz D, Bushkin I, Dror R, Zick Y. The insulinomimetic agents $\mathrm{H}_{2} \mathrm{O}_{2}$ and vanadate stimulate tyrosine phosphorylation in intact cells. $J$ Biol Chem 1990; 265: 2896-2902.

27. Faure R, Bquiran G, Bergeron JJ, Posner BI. The dephosphorylation of insulin and epidermal growth factor receptors. Role of endosome associated phophotyrosine phosphatase(s). J Biol Chem 1992; 267: 11215-11221.

28. Alexander DR. The role of phosphatases in signal transduction. News Biol 1990; 2: 1049-1062.

29. Atkinson TP, Lee CW, Rhee SG, Hohman RJ. Orthovanadate induces translocation of phospholipase $\mathrm{C}-\gamma 1$ and $-\gamma 2$ in permeabilized mast cells. J Immunol 1993; 151: 1448-1455.

30. Chao W, Liu H, Hanahan DJ, Olson MS. Protein tyrosine phosphorylation and regulation of the receptor for platelet-activating factor in rat Kupffer cells. Effect of sodium vanadate. Biochem J 1992; 288: 777784.

31. Savineau JP, Gonzalez De La Fuente P, Marthan R. Effect of modulators of tyrosine kinase activity on agonist-induced contraction in the rat pulmonary vascular smooth muscle. Pulmonary Pharmacol 1996; 9: 189-195. 